\title{
Força e consenso como fundamentos do Estado Pareto e Gramsci
}

Nas primeiras décadas do século XX a crise da democracia liberal italiana era evidente. A Itália, unificada sob a direção do liberalismo piemontês, encerrava em seu seio as mais agudas contradições. No momento da unificação, apenas $1,8 \%$ da população compunha o eleitorado ativo, e o analfabetismo atingia mais de 75\% dela (ALBERTONI, 1985, p. 299). O conflito com a Igreja católica, a chamada questão vaticana, marcou os primeiros anos do novo Estado unitário, assim como as frequentes explosões de rebeldia popular no Mezzogiorno, expressões mais evidentes da questão meridional. A resposta autoritária de Francesco Crispi no final do século XIX esteve longe de resolver esses problemas e viu ainda o surgimento de um terceiro: a questão operária. ${ }^{1}$

Foi apenas com o reformismo liberal de Giovanni Giolitti e a incorporação à vida política nacional dos católicos e dos socialistas moderados que o liberalismo encontrou, enfim, alguns anos de estabilidade. ${ }^{2}$ Mas pouco após Giolitti concluir, em 1913, a aliança eleitoral com os católicos, a qual lhe daria uma maioria confortável no Parlamento, e de tornar o sufrágio masculino universal, teve início a guerra mundial. O conflito bélico teve consequências dramáticas em toda a Europa e, particularmente, na Itália.

Francesco Crispi, presidente do Conselho de Ministros em 1887-1891 e 1893-1896, recorreu à lei marcial e estimulou um projeto imperialista no norte da Itália.

2 Giovanni Giolliti foi presidente do Conselho de Ministros por cinco vezes: 1892-1893, 1903-1905, 1906-1909, 1911-1914, 1920-1921. 
Mais de 600 mil italianos morreram no fronte sem que isso tivesse resultado nos ganhos políticos ou territoriais desejados pelos governantes. A expansão do aparelho produtivo durante o conflito teve como consequência imediata o fortalecimento do movimento operário e das alas mais radicais no interior do Partido Socialista. As greves com ocupação de fábricas durante o biennio rosso (1919-1920) mostraram um novo movimento operário na cidade e no campo, e a fundação do Partito Comunista d'Italia, em 1921, revelou as novas formas políticas que este assumia.

Em meio à agitação operária, Vilfredo Pareto escreveu um conjunto de quatro artigos, publicados em 1920 na Rivista di Milano e depois reunidos em um livro intitulado La trasformazione della democrazia, de 1921 (PARETO, 1980, p. 916-1.059). Nesses artigos, o sociólogo de Lausanne analisava as forças centrípetas e centrífugas que se faziam presentes no âmbito dos Estados. Sua preocupação voltava-se para estas últimas e identificava nas "greves de solidariedade" uma daquelas formas de "pequenas soberanias particulares" que caracterizavam as forças centrífugas presentes na política contemporânea (PARETO, 1980, p. 945).

O sociólogo identificava a sede dessas pequenas soberanias principalmente em duas classes sociais: os ricos especuladores e os trabalhadores; a primeira delas identificada com a "plutocracia" e a segunda, com a "democracia”. Mas era na aliança parcial entre essas duas forças centrífugas que Pareto identificava a ameaça à soberania central. Embora especuladores e trabalhadores não tivessem os mesmos interesses, uma parte deles operava do mesmo modo, agindo nos parlamentos modernos com vistas a impor ao Estado seus interesses particulares. O juízo desse autor sobre a democracia liberal era, assim, dos mais duros e culminava na identificação desta com o governo da "plutocracia demagógica" (PARETO, 1980, p. 949 e 955).

Pareto não era uma voz isolada. Em 1925, Gaetano Mosca constatava, bastante consternado, que o regime democrático representativo havia perdido no século XX boa parte do prestígio e da confiança de que gozou no século XIX. As razões desse descrédito seriam diversas, como a frustração da esperança de que o sufrágio universal e a igualdade política pudessem acabar ou ao menos reduzir as desigualdades econômicas e culturais; ou a queda da qualidade intelectual e moral dos eleitos decorrente do alargamento do corpo eleitoral (MOSCA, 1949, p. 307-307). Mas a ameaça mais grave 
à democracia provinha do forte impacto negativo da guerra sobre a classe média que cada vez mais perdia sua importância.

Os riscos vislumbrados por Mosca eram semelhantes àqueles identificados por Pareto: a degeneração da democracia em uma "plutocracia ou uma demagogia, ou o que é ainda pior, em um híbrido e diria quase monstruoso casamento de uma com a outra" (MOSCA, 1949, p. 308). O autor dos Elementi de scienza politica também protestava contra os sindicatos e seu poder de organizar greves, os quais representavam uma forma de "soberania intermediária entre os indivíduos e o Estado similar aquelas características do regime feudal" (MOSCA, 1949, p. 313).

Esse contexto político e intelectual permite compreender o artigo de Benito Mussolini, intitulado "Forza e consenso", publicado em 1923, na revista fascista Gerarchia. O alvo do então chefe do governo do Reino da Itália era a oposição liberal ao fascismo. Contra esta, Mussolini afirmava que a liberdade não era um fim, era um meio e como tal deveria ser "controlada e dominada". O consenso não seria, entretanto, um meio eficaz para manter a liberdade sob controle, uma vez que ele seria "mutável como a forma da areia à beiramar”. Além disso, o consenso não existiria sempre, nem seria total, uma vez que sempre haveria descontentes. Mas o que fazer, então, com estes? Como fazer para que o descontentamento não fosse uma ameaça para o governo? "Evitá-lo com a força" era a receita para o chefe dos fascistas; "empregar a força inexoravelmente quando se torne necessário". Sem a força um governo seria vulnerável ao primeiro grupo que decidisse abatê-lo. Era necessário, então, escrevia Mussolini, precaver-se: quando "um grupo ou partido está no poder, ele tem a obrigação de fortificar-se e defender-se contra todos." (MUSSOLINI, 1934a, p. 79.)

O tema era evidentemente maquiaveliano, embora o autor do artigo não citasse o secretário florentino. Mas, no prefácio que escreveu a sua tese de láurea sobre Maquiavel, publicado pela revista Gerarchia em 1924, o mesmo Mussolini reconheceu a inspiração:

É, portanto, imanente (...) o dissídio entre a força organizada do Estado e a fragmentação dos indivíduos e dos grupos. Regimes exclusivamente consensuais nunca existiram, não existem, provavelmente não existirão nunca. Muito antes de meu agora famoso artigo "Forza e consenso", Maquiavel escreveu em Il Principe, página 32: “Disso 
decorre que todos os profetas armados venceram e os desarmados se arruinaram". Porque a natureza dos povos é diversa e é fácil persuadi-los de uma coisa, mas é difícil que permaneçam naquela persuasão. (MUSSOLINI, 1934b, p. 110)3

Mussolini não foi o primeiro nem o último a reivindicar Maquiavel com o propósito de discutir a relação entre força e consenso como fundamentos do Estado, mas ao fazê-lo naquele contexto na condição de chefe de governo e na revista cultural oficial do fascismo tornou o secretário florentino uma referência incontornável no debate. A obra de Maquiavel foi também, por essa razão, um lugar do conflito. Em torno de interpretações a seu respeito, se alinharam forças políticas e se mobilizaram-se partidos. A análise dos comentários de Vilfredo Pareto e Antonio Gramsci sobre esse tema ajudarão a compreender melhor esse embate.

\section{La verità effettuale della cosa}

As diferenças teórico-políticas entre Pareto e Gramsci longe de representarem empecilhos são precisamente os motivos que nos levam a propor a análise do lugar ocupado pela força e pelo consenso como fundamentos do Estado no edifício conceitual de cada um dos autores. Isto porque ambos tomam como ponto de partida uma mesma tradição do pensamento político, a tradição maquiaveliana, traduzindo-a em linguagens teóricas que, embora partilhem alguns vocábulos, possuem uma gramática completamente diferente.

Vários comentadores destacaram a existência de uma herança maquiaveliana notável nos principais expoentes da ciência política italiana do início do século XX (BURNHAM, 1943; HUGHES, 1979; e MEDICI, 1990). O principal ponto de contato entre o pensamento político do florentino e seus herdeiros modernos tem sido definido como o "realismo maquiaveliano". Este realismo proposto por Maquiavel em Il Principe caracteriza-se, sobretudo, por tomar a "verità effettuale della cosa" como um princípio metodológico indispensável (MACHIAVELLI, 1971, p. 280). O realismo metodológico, o conhecimento dos fatos políticos tal como eles se dão na história, isto é, por meio de uma análise histórica objetiva, desapaixonada, que exclui valores

\footnotetext{
Mussolini citou a mesma passagem de Maquiavel em um discurso de 1930 - "o direito, se não é acompanhado pela força, é uma palavra vã, e o nosso grande Nicolau Maquiavel advertia que os profetas desarmados perecem" (1934c, p. 206) - e citou seu próprio texto, conhecido como "Preludio al Machiavelli", em um artigo de 1937, no qual definia a democracia como uma "ilusão inútil e uma soberania ridícula" (MUSSOLINI, 1939, p. 346-347).
} 
éticos ou ideais fictícios, seria o pressuposto de um realismo político. ${ }^{4} \mathrm{O}$ secretário florentino perceberia, assim, uma constante permanência na história da distinção entre dois tipos de homens: o tipo dirigente e o tipo dominado, sendo que o último constitui a maioria. Segundo Burnham (1943, p. 58), Maquiavel, como todos os seus seguidores considerava que essa distinção "reflete um fato basilar da vida política".

Pareto está muito próximo de Maquiavel ao assentar na natureza humana sua distinção entre aqueles que governam e os que são governados. O sociólogo de Lausanne procurava analisar os eventos políticos em sua concretude histórica, refutando tanto as análises normativas do direito quanto a metafísica positivista ou idealista presentes no contexto teórico da passagem do século XIX para o XX. ${ }^{5}$ Inaugurou, assim, juntamente com Gaetano Mosca uma nova tradição de pensamento que permitiu à ciência política tornar-se autônoma em relação às ciências jurídicas e históricas (ALBERTONI, 1985, p. 323). Ao reivindicar uma ciência livre de ideais fictícios, calcada na observação empírica e histórica, Pareto passava a compreender a divisão entre governantes e governados - evento recorrente na história e concretamente observável - como uma realidade imutável, correspondente às divisões do gênero humano.

Gramsci igualmente reivindicava a verità effettuale della cosa como princípio da análise política, mas se diferenciava sensivelmente do sociólogo. Para Gramsci, o conhecimento das realidades políticas somente era possível por meio da análise da totalidade e da complexidade das relações sociais em seu movimento histórico. Sendo assim, tratar da ciência política era "estabelecer a posição dialética da atividade política (e da ciência correspondente)"

\footnotetext{
4 O realismo maquiaveliano é melhor entendido à luz do contexto italiano do início do século XV, quando o gênero literário, que consistia em dar conselhos aos potestà e aos magistrados urbanos, se pautava pela defesa da liberdade e da justiça como valores supremos da vida e da política. Maquiavel, ao romper com a moral da época - a moral cristã - prescrevendo como formas de manter o poder não as virtudes ligadas à justiça e a liberdade, mas os meios mais efetivos, entre eles a fraude, torna-se um divisor de águas (SKINNER, 1999, p. 149-155).

Segundo Bellamy (1988, p. 10) "Pareto e Mosca rejeitaram as implicações metafísicas do positivismo, apesar do estudo da psicologia humana e da crença num empirismo cru que perduraram na base de seu entendimento das instituições políticas". Hughes sublinha que a reação contra o positivismo foi uma marca dos maiores pensadores da década de 1890. Esta reação não se dirigiu apenas contra as doutrinas de Augusto Comte e a filosofia de Herbert Spencer, mas contra toda a tendência de analisar o comportamento humano em termos análogos às ciências naturais. Diz o autor: "eles acreditavam que estavam se desfazendo de um jugo espiritual que o quarto de século precedente havia lançado sobre eles" (HUGHES, 1979, p. 37).
} 
(GRAMSCI, 1975, p. 1.568). Neste sentido, Maquiavel teria fundado a "questão da política como ciência autônoma", o que para Gramsci permite uma "concepção sistemática (coerente e consequente) do mundo - numa filosofia da práxis" (GRAMSCI, 1975, p. 1.568). O marxista sardo chamava a atenção para a necessidade de compreensão da gênese dos fenômenos que aparecem na superfície do tecido social enquanto fatos sociais "naturalizados" (SGAMBATI, 1977, p. 609) e para a necessidade de compreensão das implicações teórico-políticas da ciência social que se pauta pela visão estática da realidade, de forma que as causas da divisão entre governantes e governados, fenômeno histórico e observável, não deveriam ser tomadas como uma verdade imutável, e sim como um fenômeno histórico político.

\section{A metáfora do Centauro}

Os temas e problemas abordados por Maquiavel acerca "das boas leis e das boas armas" como fundamento do Estado claramente se encontram reelaborados nas obras de maturidade de Pareto e Gramsci, isto é, no Trattato di sociologia generale e nos Quaderni del carcere, respectivamente. Contudo, esta herança apresenta-se diversamente traduzida em cada um dos autores. Enquanto Gramsci "atualiza” o realismo maquiaveliano, associando-o à filosofia da práxis e aplicando-o a problemas contemporâneos, utilizando o príncipe prevalentemente como metáfora do moderno condottiere, isto é, do partido político (MEDICI, 1990, p. 201, 209-213), em Pareto evidencia-se uma adesão muito próxima à letra do texto de Maquiavel (MEDICI, 1990, p. 29-30).

Em Il Principe, a fórmula "boas leis e boas armas" aparece em duas passagens chaves para o tratamento deste tema, a primeira delas expressa no capítulo XII: "Os principais fundamentos comuns a todos os estados, tanto novos como velhos ou mistos, são as boas leis e as boas armas, (...) porque não pode haver boas leis onde não há boas armas, e onde há boas armas convém que haja boas leis" (MACHIAVELLI, 1971, p. 275). Mais além, no capítulo XVIII, o tema é desenvolvido em uma longa passagem:

Deveis, portanto, saber como são os dois os gêneros de combate: um com as leis, outro com a força. O primeiro é próprio do homem, e o segundo dos animais, mas porque o primeiro muitas vezes não basta, convém recorrer ao segundo: portanto, a um príncipe é necessário saber usar o animal e o homem. Esta parte foi ensinada aos príncipes secretamente pelos escritores antigos, os quais escrevem como Aquiles e 
muitos outros daqueles príncipes antigos foram alimentados pelo centauro Quíron, para que sob a sua disciplina os educasse. $\mathrm{O}$ que não quer dizer ter por predecessor um meio animal e um meio homem e sim a necessidade que um príncipe tem de saber usar uma e outra natureza, e que uma sem a outra não é durável. Sendo, pois, necessário a um príncipe saber bem usar o animal, deve tomar deste por modelos a raposa e o leão: porque o leão não se defende das armadilhas, e a raposa não se defende dos lobos. Necessita-se, pois, ser raposa para conhecer as armadilhas e leão para amedrontar os lobos. Aqueles que são somente leão não serão bem-sucedidos. (MACHIAVELLI, 1971, p. 283)

A definição da política por meio do atributo ferino e humano do Centauro maquiaveliano aparecerá tanto no pensamento político de Gramsci, para caracterizar o Estado moderno, quanto na sociologia de Pareto, para distinguir as elites governantes, bem como para expor as condições em que o governo pode ser duradouro. Contudo, a leitura da obra de Maquiavel será configurada de maneira bastante diversa em cada um dos autores. Para Pareto "em toda a história força e consenso aparecem como meios de governo" (PARETO, 1923, T, v. 3, \$2251, p. 388) ${ }^{6}$. A força é central no pensamento político do autor porquanto consiste na base da estabilidade do governo, isto é,

onde a classe governante não sabe, não quer, não pode usar a força para reprimir as transgressões à uniformidade na vida privada, cumpre a tarefa anárquica dos governados (...). Observa-se que, onde é débil a atuação do poder público, constituem-se pequenos Estados entre o grande Estado, pequenas sociedades entre uma maior. Similarmente, onde ocorre menor atuação da justiça pública, é substituída pela justiça privada, sectária, e vice-versa (...). Gravíssima ilusão é aquela dos homens políticos que imaginam poder substituir com desarmadas leis ao uso da força armada. (PARETO, 1923$, T, v. $3, \S 2.180$, p. $342-346)^{7}$

De acordo com Pareto, as leis não poderiam substituir as armas sob pena da desintegração do Estado. Ao contrário, as armas deveriam garantir a eficácia das leis, dizia Pareto: "na sociedade, o direito para ser uma realidade necessita da força. Quer se tenha desenvolvido espontaneamente, ou seja, obra de uma minoria será imposto aos dissidentes apenas com a

6 Para simplificação do texto, citaremos Pareto no Trattato di sociologia generale utilizando a letra "T", seguida do volume de referência, do parágrafo e da página.

Pareto retoma aqui a crítica às soberanias privadas mencionada anteriormente. 
força" (PARETO, 1974, p. 155). Entre as armas e as leis, portanto, deveria haver uma relação de complementaridade, contudo, a força aparece como pressuposto do direito, o que nos remeteria diretamente a Maquiavel, isto é "não pode haver boas leis onde não há boas armas e onde há boas armas convém que haja boas leis".

O consenso, no sentido em que este autor emprega, significa, sobretudo, persuasão. Esta não se contraporia à força, mas seria, justamente, um meio para assegurar a força. Contudo, "não são persuadidos todos os membros de uma sociedade, sem exceção; para assegurar o sucesso, é persuadida apenas uma parte deles: a parte que tem a força, ou que é a mais numerosa, ou por outras razões". Neste sentido, a persuasão orientar-se-ia pela força, isto é, deveria convencer aqueles que podem oferecer resistência efetiva ao governo. Diz o autor "é com a força que as instituições sociais se estabelecem; é com a força que se mantém" (PARETO, 1974, p. 156). Desta forma, a persuasão evitaria o embate direto entre o governo e os membros da sociedade que teriam força para fazer-lhe oposição.

Conforme sublinha Sgambati (1977, p. 615), o conceito de consenso utilizado pelos elitistas não deve ser identificado com um meio de ativação política e intelectual da massa, pelo contrário, ele assume uma forma muito mediada pela força, tornando-se efetivamente "o meio para a conservação de um estático equilíbrio das relações sociais vigentes”. Pareto identifica o consenso à astúcia, de forma que há uma identidade quase total entre persuadir e enganar. Deste modo, segundo Medici, "talvez sem perceber, Pareto transforme a imagem semiferina da política, presente no Centauro maquiaveliano, em uma imagem totalmente ferina (a raposa e o leão), anulando quase totalmente aquele lado humano que Maquiavel conservava" (MEDICI, 1990, p. 53-54). De acordo com Pareto:

Para impedir a violência ou para resisti-la, a classe governante usa a astúcia, a fraude, a corrupção, e, em poucas palavras, o governo passa dos leões às raposas. A classe governante curva-se diante da ameaça da violência, mas cede somente na aparência e busca remover o obstáculo que não pode superar abertamente. (PARETO, 1923, T, v. 3, $\$ 2.178$, p. 339).

Desta forma, para Pareto aquele que melhor conhece "a arte de debilitar os adversários com a corrupção, de remover com a fraude e com o engano 
aquilo que parecia ter cedido à força é ótimo entre os governantes", por outro lado, quem perdeu a resistência e "não sabe se dobrar no tempo e lugar adequados é péssimo entre os governantes” (PARETO, 1923, T, v. 3, \$2.178, p. 339). Por esta razão - diz o autor - na classe governante, crescem os resíduos dos instintos das combinações (classe I) ${ }^{8}$ - relacionados à astúcia, isto é, a natureza da raposa - que comportam o espírito de inovação mais associados às elites governantes (PARETO, 1923, T, v. $3, \S 2.178$ e $\$ 2.227$, p. 339 e p. 374-375; MEDICI, 1990, p. 52-53; LOSURDO, 2006, p. 250; BONETTI, 1994, p. 60). Estas proposições nos remetem mais uma vez à Maquiavel, para o qual "aquele que soube melhor usar a raposa teve melhor resultado" (MACHIVELLI, 1971, p. 283).

Como se sabe, Pareto foi um liberal conservador, cuja trajetória intelectual passou por uma paulatina "transformação". Em grande medida inspirado pela experiência inglesa das conquistas alcançadas mediante a liga Anticorn Law, movimento inglês pela liberdade de comércio "nascido de baixo por um espontâneo sentimento de justiça e de revolta contra os irracionais privilégios de uma minoria" (BONETTI, 1994, p. 6), o autor professava na juventude uma sólida crença na conquista de direitos sociais mediante a participação democrática dos setores populares. Contudo, suas expectativas não encontraram acolhimento no contexto político italiano - onde não existia nem uma classe empreendedora comparável à inglesa e nem um sistema político fundado sobre um efetivo bipartidarismo -, o que acabou por levá-lo ao ceticismo acerca da capacidade dos italianos em conquistar os próprios direitos com a luta pacífica sem invocar o governo, isto é, sem esperar uma "benévola concessão soberana" (BONETTI, 1994, p. 6).

\footnotetext{
8 Dois conceitos são centrais para a ciência lógico-experimental formulada por Pareto no Trattato di sociologia generale: os resíduos e as derivações. Os resíduos não são os sentimentos ou o estado psíquico em si, mas elementos intermediários entre os sentimentos que não conhecemos diretamente e as suas expressões. Eles se relacionam com os instintos do homem, mas não abrangem a todos, pois o método não permite descobrir que instintos dão lugar aos raciocínios. Além dos resíduos, existem, portanto, apetites, gostos, inclinações e interesses. Os resíduos são classificados em seis classes: I. Instinto das combinações, II. Persistência dos agregados, III. Necessidade de manifestar os sentimentos com atos externos, IV. Resíduos em relação à sociabilidade, V. Integridade do indivíduo e de suas dependências e VI. Resíduo sexual (PARETO, 1923, T, v. 2, § 888, p. 15-17; ARON, 2000, p. 385-386). As derivações representam - na linguagem de Pareto - o equivalente do que correntemente se chama de ideologia. Elas consistem nos diferentes meios verbais pelos quais os indivíduos fornecem uma lógica aparente àquilo que, na verdade, não tem tanta lógica quanto os atores fazem parecer (PARETO, 1923, T, v. 2, § 1.419, p. 340; ARON, 2000, p. 397).
} 
O ideal de juventude da estreita relação entre instrução popular e bom governo foi, assim, completamente renegado. É possível perceber no desenvolvimento de seu pensamento uma sensível substituição da crença na "virtù redentora da ciência difusa entre os setores populares" (BONETTI, 1994, p. 7) por uma visão cética da política como efetiva atividade de minorias dirigentes, de forma que as grandes revoluções - no julgamento do autor - não seriam mais que a luta de novas elites para substituir as antigas (HUGHES, 1979, p. 81). Nesta última perspectiva o tema da força ganhou centralidade como um elemento importante para a manutenção dos governos, ainda que estes "assegurem ter fundamento na razão" (BONETTI, 1994, p. 171).

Essa revalorização da força coincidiu com a adesão de Pareto ao fascismo. Segundo o sociólogo, para evitar as tendências que conduziam a sociedade italiana em direção a um estado similar ao comunismo, a resistência dos governos anteriores "navegando nas águas inseguras do parlamentarismo" haviam se mostrado ineficazes. Mas o fascismo, "pronto a usar a força, última razão dos partidos e das nações”, era uma solução, senão a melhor, pelo menos uma solução eficaz (PARETO, 1980, p. 1151).

Mas se por um lado, a força garantiria o estabelecimento e a manutenção das instituições sociais - assim como a eficácia do direito -, a astúcia e a fraude deveriam manter o equilíbrio social por meio da persuasão de indivíduos ou grupos que, na classe governada, estivessem dispostos a usar da violência para substituir a classe governante. $\mathrm{O}$ autor sublinhava que se a classe governante possuísse habilidade no uso da astúcia e da fraude e conseguisse com isto "assimilar o maior número daqueles que, na classe governada, têm os mesmos dotes, que sabem usar as mesmas artes, e que, portanto, poderiam ser os líderes daqueles que estão dispostos a usar a violência”, ela certamente conseguirá manter um governo forte e estável (PARETO, 1923, T, v. 3, \$2.179, p. 340).

O êxito do governo, portanto, dependeria da renovação das elites por meio da capacidade de assimilar os elementos ativos dentre os governados. Esta renovação possuiria uma dupla função: por um lado evitaria que se estabelecesse uma profunda diferença entre os resíduos prevalecentes entre os governados e entre os governantes ${ }^{9}$; por outro lado e em decorrência,

Os resíduos de segunda classe (persistência dos agregados), cuja característica é a "veneração" da comunidade política ou religiosa, encontrar-se-iam mais difundidos entre a massa de governados, 
tornaria menos prováveis as sublevações violentas dos estratos populares. De acordo com Pareto:

Para manter a estabilidade na sociedade, basta à classe governante acrescentar a si um número restrito de indivíduos, para tirar os líderes da classe governada. Entretanto, no longo prazo, cresce a diferença de índole entre a classe governante e a governada; naquela há inclinações ao prevalecer dos instintos das combinações, nesta dos instintos de persistência dos agregados; e, quando a diferença torna-se suficientemente grande, ocorrem revoluções. (PARETO, 1923, T, v. 3, \$2.179, p. 340-341)

A renovação das elites representa, portanto, um justo equilíbrio entre o leão e a raposa no seio da classe governante, isto é, da capacidade de equilibrar a força e a fraude: força para manter o governo e a astúcia para fortalecer-se e ao mesmo tempo enfraquecer os movimentos vindos de baixo pela assimilação de seus líderes à elite governante, de forma que a classe governante que não se renova sofra um afrouxamento da sua capacidade de direção (PARETO, 1923, T, v.3, $\$ \$ 2.055-2.059$, p. 263; ARON, 2000, p. 418). A atualização das elites, ou, para utilizar o termo presente no Trattato, a "circulação das elites", constitui um processo regular na vida do Estado, isto é, é um imperativo do equilíbrio social no sistema paretiano.

Embora não tivesse o livro na prisão, Antonio Gramsci conhecia o Trattato paretiano chegando a referir-se a ele diretamente em várias oportunidades ao longo dos Quaderni del carcere. O diálogo que procura estabelecer com o sociólogo de Lausanne não tem, entretanto, sua cadência ditada pela pesada lógica da exposição do Trattato, e sim pelos grandes temas enfrentados nele e, particularmente, este da relação necessária entre força e do consenso no âmbito da política. O tema, como visto anteriormente, não é de exclusividade desses dois autores, mas é parte do debate político da época.

Os parágrafos dos Quaderni del carcere, nos quais Antonio Gramsci tratou diretamente dessa temática são, em sua maioria, textos de única escritura (textos B) e textos de primeira redação (textos A) retomados no caderno 13, que reúne as Noterelle sulla política del Machiavelli. A primeira referência ao tema maquiaveliano da força e do consenso encontra-se em uma nota escrita 
entre fevereiro e março de $1930^{10}$ no Primo quaderno $(\$ 48)^{11}$, retomada no Quaderno 13 (\$37), redigida (com pequenas reformulações que não alteram o conteúdo) entre 1932 e 1934. Nesta nota, a combinação e o equilíbrio entre a força e o consenso definem o conceito de hegemonia:

o exercício "normal" da hegemonia no terreno tornado clássico pelo regime parlamentar é caracterizado por uma combinação da força e do consenso que se equilibram, sem que a força suplante em muito o consenso, ao contrário, apareça apoiada pelo consenso da maioria expresso pelos assim ditos órgãos da opinião pública (o quais por isso, em certas situações, multiplicam-se artificialmente). Entre o consenso e a força está a corrupção-fraude (que é característica de certas situações de difícil exercício da função hegemônica, apresentando o exercício da força excessivos perigos), isto é, o enfraquecimento e a paralisia do antagonista ou dos antagonistas causada pela absorção dos seus dirigentes (...). (GRAMSCI, 1975, Q 1, §48, p. 59).

Esse parágrafo é particularmente esclarecedor porquanto articula à força e ao consenso noções e conceitos chaves para o tratamento do tema como hegemonia, opinião pública e a corrupção-fraude. Por esta razão, voltaremos a esse parágrafo recorrentemente para melhor discutir essas noções aqui mencionadas e desenvolvidas em outras notas dos Quaderni. Devemos, portanto, em primeiro lugar esclarecer a relação entre hegemonia, força e consenso.

A hegemonia política e cultural de determinada classe se caracteriza pela construção de uma direção consentida entre grupos aliados na sociedade civil e pela coerção por meio do aparelho repressivo de Estado sobre os grupos que não consentem nem ativa e nem passivamente. Neste sentido, o consenso permite à classe ser dirigente, enquanto a força torna-a dominante. No mesmo Primo quaderno, no $\$ 44$, de 1930 , Gramsci se refere à hegemonia como direção e dominação de classe:

O critério histórico-político sobre o qual há necessidade de fundar as próprias pesquisas é este: que uma classe é dominante de dois modos, isto é, é "dirigente" e "dominante". É dirigente das classes aliadas e dominante das classes adversárias (...).

${ }^{10}$ Conferir Francioni (1984, p. 141). Toda datação adotada no presente texto tomará como referência aquela estabelecida por Gianni Francioni (1984), de forma que não incorporaremos as referências ao autor no corpo do texto com vistas à simplificação das citações.

1 Para simplificação do texto citaremos Gramsci nos Quaderni del cárcere utilizando a letra "Q", seguida do número do caderno, do parágrafo e da página de referência. 
Pode-se e deve-se ser uma "hegemonia política" também antes da chegada ao Governo e não há necessidade de fundar somente sobre o poder e sobre a força material que ele proporciona para exercitar a direção ou hegemonia política. (GRAMSCI, 1975, Q 1, §44, p. 41).

Note-se que o termo hegemonia aparece tanto como direção e dominação de classe, quanto como sinônimo de consenso ou de direção de uma classe ou grupo social sobre as classes e grupos aliados antes da chegada ao governo. $\mathrm{O}$ aspecto mais importante a ressaltar, contudo, é que a reflexão sobre hegemonia, que articula força e consenso, é precisamente uma reflexão sobre o Estado, isto é, sobre como o equilíbrio instável das relações de forças sociais se estabelece entre os diversos grupos na sociedade civil em disputa pela direção do aparelho estatal.

No Quaderno 6, em uma nota de escritura única redigida entre março e agosto de 1931, encontramos a seguinte formulação: "Estado = sociedade política + sociedade civil, ou seja, hegemonia encouraçada de coerção" (GRAMSCI, 1975, Q 6, §88, p. 763-764). O Estado, de acordo com a formulação de Gramsci, não se resume ao aparelho governamental encarregado da administração direta e do exercício legal da coerção, ele inclui também a esfera civil, na qual os aparelhos privados de hegemonia possuem sua sede. Cada uma das esferas possui características próprias e não se confundem entre si; contudo, a distinção entre elas só poderá ser metodológica porquanto estão organicamente ligadas. Deste modo, compreende-se que, na concepção gramsciana de Estado, sociedade política e sociedade civil estão em relação de unidade-distinção. Esta relação define de forma apropriada também a ligação entre força e consenso.

A metáfora do "Centauro maquiavélico" utilizada por Gramsci no Quaderno 13 fornece uma imagem clara da ligação orgânica que se estabelece entre sociedade civil e sociedade política, bem como entre força e consenso:

Outro ponto a ser fixado e desenvolvido é o da "dupla perspectiva" na ação política e na vida estatal. Vários são os graus através dos quais se pode apresentar a dupla perspectiva, dos mais elementares aos mais complexos. Mas eles podem se reduzir teoricamente a dois graus fundamentais correspondentes à natureza dúplice do Centauro maquiavélico, férica e humana, da força e do consenso, da autoridade e da hegemonia, da violência e da civilidade, do momento individual e daquele universal 
(da "Igreja" e do "Estado"), da agitação e da propaganda, da tática e da estratégia. (GRAMSCI, 1975, Q 13, §14, p. 1.576) ${ }^{12}$

Da mesma maneira que não seria possível a divisão do Centauro de forma a separar a fera do homem sem matá-lo, é impossível separar a condição de existência do poder político de sua condição de legitimidade, isto é, a força do consenso (BIANCHI, 2008, p. 190), porquanto sua ligação é orgânica. Uma leitura apressada, contudo, poderia sugerir que Gramsci estaria relacionando simplesmente o consenso ao momento da hegemonia civil e a força ao momento da autoridade estatal, de forma que o consenso seria puramente construído na sociedade civil, e a coerção somente se faria presente por meio do aparato de Estado. Contudo, o conjunto das notas que tratam do assunto leva a tornar o quadro mais complexo. Dois textos B encontrados no Quaderno 7 ( $\$ 83$ ) e no Quaderno 8 (\$2), escritos com bastante proximidade temporal - o primeiro foi escrito em dezembro de 1931, e o segundo em janeiro de 1932 - são especialmente importantes para o esclarecimento do problema.

A noção de opinião pública - citada no Quaderno 1 ( $\$ 48)$ - reaparece no Quaderno 7 estreitamente relacionada à hegemonia política. Para Gramsci, ela é um ponto de contato entre a "sociedade civil" e a "sociedade política", entre o consenso e a força, porquanto é instrumento do Estado para "organizar e centralizar certos elementos da sociedade civil" "quando quer iniciar uma ação pouco popular” (GRAMSCI, 1975, Q 7, § 83, p. 914). Depreende-se disto que o Estado, por meio dos aparelhos públicos e privados de comunicação (portanto, também por meio dos aparelhos privados de hegemonia), prepara a aceitação na sociedade civil para determinadas medidas impopulares. Sendo assim, o uso da força pelo aparelho estatal, embora esteja sempre presente como potência, não se realizaria sem que antes se esgotassem as tentativas de direção política por meio do consenso.

\footnotetext{
12 Trata-se de uma nota de segunda escritura com pequenas alterações de um texto A - Q 8, § 86 - de março de 1932) Esta relação de unidade-distinção já estava presente numa nota de única escritura do Quaderno 6, redigida entre março e agosto de 1931, em que Gramsci faz referência a Guicciardini, contemporâneo de Maquiavel: "Afirma Guicciardini que para a vida de um Estado duas coisas são absolutamente necessárias: as armas e a religião. A fórmula de Guicciardini pode traduzir-se em várias outras fórmulas menos drásticas: força e consenso, coerção e persuasão, Estado e Igreja, sociedade política e sociedade civil, (...)" (GRAMSCI, 1975, Q 6, § 87, p. 763). Esta não deixa de ser uma referência a Maquiavel já que Guicciardini coloca a questão em um comentário aos Discorsi sopra la prima decade di Tito Lívio (BIANCHI, 2008, p. 188).
} 
No Quaderno 8, em uma nota intitulada "O Estado e a concepção do direito" Gramsci ressaltou o caráter "educador" do Estado que foi tornado possível pela "revolução operada pela burguesia na concepção do direito e, portanto, nas funções do Estado". De acordo com Gramsci, "a classe burguesa põe a si mesma como um organismo em contínuo movimento, capaz de absorver toda a sociedade, assimilando-a ao seu nível cultural e econômico: toda a função do Estado é transformada: o Estado torna-se 'educador', etc." (GRAMSCI, 1975, Q 8, § 2, p. 937). A burguesia expande-se de forma a universalizar seus interesses de classe, isto quer dizer que, para manter o consenso sobre a sociedade civil, esses interesses devem aparecer como interesses de toda a sociedade. Por meio do direito, a coerção a que o trabalhador deve estar sujeito para vender sua força de trabalho não apareceria como violenta expropriação, mas como ato voluntário de todo indivíduo que comparece no mercado como proprietário de sua própria força de trabalho, isto é, para exercer um direito. O consenso em torno da justiça e do direito, portanto, libera o Estado do uso contínuo da força para manter a reprodução do modo de produção capitalista, de forma que ele não possuiria mais apenas uma função repressora, mas também uma função educativa, de produtor de consentimento.

Sendo assim, esclarecia Gramsci, se ocorrem prisões e se retorna a concepções do Estado como pura força, é sinal de que a classe burguesa está saturada e não só não mais se difunde como se desagrega, não assimila novos elementos, mas perde partes de si mesma (GRAMSCI, 1975, Q 8, § 2, p. 937). É neste sentido que se deve entender que "o exercício 'normal' da hegemonia" é caracterizado "por um equilíbrio entre a força e o consenso" (GRAMSCI, 1975, Q 1, \$48, p. 59), na sociedade civil e na sociedade política. A definição do Estado moderno em Gramsci, portanto, tinha como pressuposto a análise do uso da força e do consenso pelas classes dominantes com vistas a manter sua hegemonia. Esta qualificação do Estado diferencia-se claramente da definição do governo de Pareto, que, embora aceitasse a noção de classes e o conflito, não admitia o caráter historicamente determinante da luta de classes, considerando-a como expressão de uma recorrente disputa entre elites e, por esta razão, o consenso não se referiria a toda a sociedade, mas apenas à parte ativa dela (PARETO, 1953, v. 2, \$1.053, p. 429).

De acordo com Gramsci, assim como a sociedade política busca a formação do consenso na sociedade civil para evitar o uso direto da força, na 
sociedade civil também se encontra algum nível de coerção combinada com o consentimento. Essa temática foi desenvolvida por Gramsci na fase final de sua elaboração nos Quaderni 14 e 22. No Quaderno 14, o marxista sardo apresentou uma nova reflexão sobre a relação entre sociedade civil e sociedade política, identificando a atividade legislativa no âmbito das duas esferas. Devido a essa dupla localização, a eficácia da atividade legislativa dependeria não apenas da possibilidade do uso dos meios coercitivos pela sociedade política, como, também, pela sociedade civil (GRAMSCI, 1975, Q 14, $\$ 13$, p. 1.668). Gramsci ilustrou essa possibilidade recorrendo ao exemplo dos Estados Unidos:

Nos Estados Unidos, legalmente e de fato não falta a liberdade religiosa dentro de certos limites, como recorda o processo contra o darwinismo, e, se legalmente (dentro de certos limites) não falta liberdade política, esta falta de fato pela pressão econômica e pela aberta violência privada. (GRAMSCI, 1975, Q 14, p. 1.666 - grifos nossos) ${ }^{13}$

Já no Quaderno 22, escrito no último período da vida de Gramsci na prisão, em 1934, o autor sublinhou que a coerção deveria ser "sabiamente combinada com a persuasão e o consenso" no interior da indústria (GRAMSCI, 1975, Q 22, \$13, p. 2.171-2.172). Desta forma, a coerção seria exercida sobre o trabalhador principalmente por meio do ritmo de trabalho imposto pela máquina e pelas longas jornadas às quais o trabalhador seria constrangido para suprir seus meios de subsistência em função dos baixos salários. A persuasão e o consenso, de acordo com Gramsci, poderiam advir da concessão de salários mais altos em momentos de adaptação a novos métodos de produção e de trabalho, de forma que tal adaptação não ocorreria “somente através da coação social” (GRAMSCI, 1975, Q 22, \$13, p. 2.171).

Uma vez esclarecido o equilíbrio entre força e consenso como exercício normal da hegemonia, deve-se perguntar quais seriam as condições e as consequências para Gramsci do desequilíbrio entre os dois elementos. Mais uma vez é necessário retornar ao $\$ 48$ do Primo quaderno, no qual o autor afirma que em momentos de difícil exercício da função hegemônica a corrupção-fraude se interpõe entre o consenso e a força. Quando a classe dominante perde o consenso, deixando de ser dirigente, mas unicamente dominante, "detentora de pura força coercitiva", abre-se o campo para a crise

13 Ver o comentário dessa passagem em Bianchi (2008, p. 197). 
de hegemonia (GRAMSCI, 1975, Q 3, § 34, p. 311-312). Nesta situação causada porque "a classe dirigente fracassou em algum grande empreendimento político para qual pediu ou impôs pela força o consenso das grandes massas (como a guerra)" ou porque as grandes massas populares saíram subitamente da passividade política e passaram a apresentar reivindicações potencialmente subversoras da ordem - "abre-se o campo para soluções de força” (GRAMSCI, 1975, Q 13, \$23, p. 1.603).

Uma vez que as grandes massas populares não são mais convencidas pelas ideologias tradicionais que mantêm a direção política da classe dominante, resta a esta soluções de força, isto é, o uso da característica ferina do Centauro, que devemos lembrar é composta tanto pelo leão quanto pela raposa, isto é, pela força associada à astúcia, ao engano, ou, à corrupção-fraude na terminologia de Gramsci. A corrupção-fraude, que se interpõe entre a força e o consenso, consiste precisamente no enfraquecimento e na paralisia do antagonista "causada pela absorção de seus dirigentes, veladamente em via normal, abertamente em caso de perigo iminente, para lançar a confusão nas fileiras adversárias" (GRAMSCI, 1975, Q $1, \S 48$, p. 59).

Este processo - que como vimos, Pareto entendia ser uma atividade regular da elite dirigente para manutenção do Estado - Gramsci denominava "transformismo", que sugere, ao contrário, uma preponderância da força em detrimento da política. Neste sentido, o uso da força por meio da corrupçãofraude permitiria às elites impedir as transformações radicais da sociedade, neutralizando as forças populares por meio da absorção molecular - no Estado - de indivíduos ou de grupos inteiros, esvaziando, contudo, qualquer conteúdo revolucionário destes grupos (GRAMSCI, 1975, Q 8, § 36, p. 962963). Neste sentido, o consenso, isto é, o consentimento a determinada direção política, a face humana do Centauro - de acordo com o pensamento de Gramsci - não poderia em nenhuma hipótese ser confundido com a fraude, que é uma expressão da força, do elemento ferino do Centauro.

\section{Conclusão}

As interpretações antagônicas de Gramsci e Pareto acerca do mesmo processo de absorção molecular dos líderes dos governados na elite governante se devem, como fica evidente, às diferentes perspectivas sobre as relações estabelecidas entre força e consenso como fundamentos do Estado. Assim, enquanto Pareto entende que o consenso, isto é, a persuasão, é mediada pela 
força, para Gramsci, conforme procuramos demonstrar, deve haver um justo equilíbrio entre a natureza humana e a ferina para que a política não seja suplantada pela força.

Sendo assim, enquanto no pensamento político de Pareto o consenso assume uma função acentuadamente instrumental (SGAMBATI, 1977, p. 614), que claramente entende a política sob a perspectiva das elites governantes e preocupa-se, sobretudo, com a conservação e com a estabilidade social, em Gramsci o consenso é entendido como meio de ativação política e intelectual da massa dos governados com vistas à transformação da ordem social. Nesta perspectiva, Maquiavel é particularmente importante como fundador da ciência e da arte política que devem orientar a ação do "novo príncipe”, isto é, do partido político organizador de uma nova hegemonia.

Esta inovadora perspectiva popular de Il Principe torna Gramsci um herdeiro sui generis de Maquiavel na medida em que os neomaquiavelianos elitistas - Mosca, Pareto e Michels - entenderam a política sob a perspectiva dos governantes. De acordo com Medici (1990, p. 13), esta consideração faz vislumbrar a necessidade de distinguir o que poderia ser uma consciente adesão à obra de Maquiavel como ocorre com Pareto, ou uma relação "metafórica”, que reelabora de forma original o pensamento do florentino, como faz Gramsci. É preciso sublinhar, entretanto, que ambas as perspectivas, bem como o seu confronto, redundam, sobretudo, em avanços importantes para a teoria e para a prática política contemporânea. A preocupação de Maquiavel com a duração do poder não permite que o caráter conflitivo da política - que consiste num tenso equilíbrio entre força e consenso - seja negligenciado. A despeito dos desacordos teóricos e políticos e das perspectivas antagônicas de Pareto e Gramsci, o conflito como característica fundamental da esfera política se faz fortemente presente na obra de ambos os autores, conferindolhes a complexidade e o rigor que a análise teórica e política requer.

\section{Referências bibliográficas}

ALBERTONI, Ettore A. 1985. Storia delle dottrine politiche in Itália. Milão: Arnoldo Mondadori Editore.

ARON, Raymond. 2000. As etapas do pensamento sociológico. São Paulo: Martins Fontes.

BIANCHI, Alvaro. 2008. O laboratório de Gramsci: filosofia, história e política. São Paulo: Alameda. 
BELLAMY, Richard. 1988. Modern Italian social theory. Stanford: Stanford University.

BONETTI, Paolo. 1994. Il pensiero político di Pareto. Bari: Laterza.

BURNHAM, James. 1943. The machiavellians. Chicago: Gateway.

FRANCIONI, Gianni. 1984. Lofficina gramsciana: ipotesi sulla struttura dei "Quaderni del carcere". Nápoles: Bibliopolis.

GRAMSCI, Antonio. 1975. Quaderni del carcere: edizione critica dell'Istituto Gramsci a cura di Valentino Gerratana. Turim: Einaudi.

HUGHES, H. Stuart. 1979. Consciousness and society: the reorientation of European social thought 1890-1930. Brighton: Harvester.

LOSURDO, Domenico. 2006. Gramsci, do liberalismo ao "comunismo crítico". Rio de Janeiro: Revan.

MACHIAVELLI, Niccolò. 1971. Tutte le opere. Firenze: Sansoni.

MEDICI, Rita. 1990. La metáfora machiavelli: Mosca, Pareto, Michels, Gramsci. Modena: Muchi.

MOSCA, Gaetano. 1949. Partiti e sindicati nella crisi del regime parlamentare. Bari: Laterza.

MUSSOLINI, Benito. 1934a. "Forza e consenso". In: MUSSOLINI, Benedito (ed.). Scritti e discorsi: edizione definitiva. Vol. III. Milano: Ulrico Hoelpi. . 1934b. "Preludio al Machiavelli". In: MUSSOLINI, Benedito (ed.). Scritti e discorsi: edizione definitiva. Vol. IV. Milano: Ulrico Hoelpi. . 1934c. "I discorsi di Livorno, Lucca e Firenzi." In: MUSSOLINI, Benedito (ed.). Scritti e discorsi: edizione definitiva. Vol. VII. Milano: Ulrico Hoelpi.

. 1939. "Il capestro di demos". In: MUSSOLINI, Benedito (ed.).

Scritti e discorsi: edizione definitiva. Vol. XII. Milano: Ulrico Hoelpi. PARETO, Vilfredo. 1923. Trattato di sociologia generale. Firenze: G. Barbera. . 1953. Corso di economia politica. Torino: Einaudi. . 1974. Le sistemi socialisti: a cura di Giovani Busino. Torino: UTET. . 1980. Scritti sociologici minori: a cura di Giovanni Busino. Torino: UTET.

SGAMBATI, Valeria. 1977. "Per un'analisi del rapporto tra Gramsci e gli èlitisti”. In: FERRI, Franco (org.). Politica e storia in Gramsci. Vol. 2. Roma: Riuniti/ Instituto Gramsci.

SKINNER, Quentin. 1999. As fundações do pensamento político moderno. São Paulo: Companhia das Letras. 


\section{Resumo}

A definição da política por meio do atributo ferino e humano do Centauro maquiaveliano - a força e o consenso como fundamentos do Estado - aparecerá tanto no pensamento político de Gramsci para caracterizar o Estado moderno, quanto na sociologia de Pareto, para distinguir as elites governantes. Os autores, contudo, aproximam-se de Maquiavel de formas bastante diversas. Enquanto Gramsci "atualiza" o realismo maquiaveliano, associando-o ao marxismo e aplicando-o a problemas contemporâneos, em Pareto evidencia-se uma adesão muito próxima à letra do texto de Maquiavel. As diferentes leituras dos autores a respeito das relações entre força e consenso, não obstante a coincidência da fonte maquiaveliana, desembocarão em perspectivas antagônicas acerca da política e da estabilidade social.

Palavras-chaves: Vilfredo Pareto; Antonio Gramsci; Nicolau Maquiavel; força; consenso.

\section{Abstract}

The definition of politics by means of the fierce and human attribute of the Machiavellian Centaurus - power and consensus as the foundations of the State - is present both in Gramsci's political thought in order to characterize the modern State and in Pareto's sociology in view of distinguishing governing elites. The authors, nevertheless, are close to Machiavelli in very different ways. Whereas Gramsci "updates" Machiavelli's realism associating it to Marxism and applying it to contemporaneous issues, in Pareto it is evident a very close adherence to the very wording of Machiavelli's writings. Despite the coincidence of their Machiavellian source, the authors' different readings regarding the relationships between power and consensus will lead to antagonistic perspectives about politics and social stability.

Key words: Vilfredo Pareto; Antonio Gramsci; Nicollo Machiavelli; power; consensus.

Recebido em novembro de 2010.

Aprovado em janeiro de 2011. 